\title{
Effects of Heating and Acid Activation on the Structure and Surface Prop- erties of a Kaolinite-illite-smectite Clayey Mixture
}

\author{
O. Landoulsi ${ }^{1}$, A. Megriche ${ }^{1}$, R. Calvet $^{2}$, F. Espitalier ${ }^{2}$, J.M.F. Ferreira ${ }^{3}$ and A. Mgaidi ${ }^{1,4, *}$ \\ ${ }^{1}$ Industrial laboratory -Faculty of sciences University of El Manar Tunisia 2092 \\ ${ }^{2}$ University of Toulouse, Mines Albi, CNRS, Campus Jarlard, F-81013 Albi cedex 09, France \\ ${ }^{3}$ Ceramics and Glass Engineering Department, CICECO, University of Aveiro, 3810-193, Aveiro, Portugal \\ ${ }^{4}$ Taibah University, Faculty of Sciences \& Art Al Ula, Saudi Arabia
}

\begin{abstract}
This work aims at studying the effects of heat treatment and acid activation on the surface properties of a mixture of kaolinite-illite-smectite clay minerals collected from North Est of Tunisia. The raw material was characterized by various analytical and spectroscopic techniques such as XRD, FT-IR, TG-DSC, and $\mathrm{N}_{2}$ physical adsorption.

The true density of starting raw material increased from 2580 to $2609 \mathrm{~kg} . \mathrm{m}^{3}$, while the surface area, $\mathrm{S}_{\mathrm{BET}}$, decreased from 70.7 to $35.3 \mathrm{~m}^{2} . \mathrm{g}^{-1}$ upon heat treating at $550^{\circ} \mathrm{C}$ for $1 \mathrm{~h}$. Acid activation of heat treated material led to partial dissolution of the octahedral sheets by interlayer and edge attack, the formation of amorphous silica and an overall structural degradation. Dynamic vapour Sorption (DVS) measurement revealed that the surface energy of the system increased after acid activation and with the acid treatment time. These structural/surface changes translated in higher negative zeta potential $(\zeta)$.
\end{abstract}

Keywords: Heated clay, Acid activation, Texture, Surface energy.

\section{INTRODUCTION}

Clay's minerals are widely used in many industrial applications like paper, foundry, chemical and food industries [1]. The effects of acid attack and heat treatments on the catalytic behaviour of pure clay minerals were the subject of many earlier investigations, but only few of them have dealt with the surface properties of clay mixtures [2,3]. Madejova et al. [4] reported on the benefit of near infrared spectroscopy to study acid treated clay minerals such a layered mixture of illite/smectite and kaolinite. In their investigation, acid treatments have been performed in $6 \mathrm{M} \mathrm{HCl}$ or $0.5 \mathrm{M} \mathrm{HCl}$ under different temperatures and time periods. They concluded that the acid activation could be described as a deterioration of the clay structure exhibiting micro-porous and meso-porous areas. Recently Önal and Sarikaya [5] reported an increase of porosity and specific surface area of a smectite-palygorskite containing clay upon a heat $\left(97^{\circ} \mathrm{C}\right)$ treatment in $\mathrm{H}_{2} \mathrm{SO}_{4}$. The efficiency of clay materials with high smectite content in decolourising palm oil was enhanced after acid activation [6].

It has been reported that the heat treatment of clayey soils changed some physical and mechanical properties such as cohesion and strength [7], the textural properties of the medical Algo clay [8], and some engineering properties of clays (density, plastic and liquid limits, plasticity index, etc.)

*Address correspondence to this author at the Taibah University, Faculty of Sciences \& Art Al Ula, Saudi Arabia; Tel: +21698616609;

Fax: +216 782666; E-mail: arbi.mgaidi@fst.rnu.tn
[9]. Caturla et al. [10] reported that heat treating sepiolite at $500{ }^{\circ} \mathrm{C}$ induces permanent changes, while the original structure and properties of the starting raw material can be restored after heat treating at a temperature $\leq 300{ }^{\circ} \mathrm{C}$. The driving potential for adsorption is the clay surface energy, which is basically related to the lattice energy. However, no single experiment can give direct access to the clay mineral surface energy. All methods used so far for determining the surface energy of solids are based on liquid/solid interactions and on quantitative measurements of adsorbed molecules. They consist of measuring the flow, the pressure or the amount of adsorbed gas or of saturated hydrocarbon solutions [11]. Salles et al. [12] determined the surface energy of kaolinite and serpentine based on heat of immersion experiments by using the PACHA formalism. The authors used model clays (kaolinite and serpentine) and compared its surface energy data obtained either by solid state calculations using electronegativities equalization, or by immersion experiments. They concluded that kaolinite and serpentine have quite the same lattice energy, which can be attributed to their similar structure.

The surface pressure $\left(\pi_{\mathrm{e}}\right)$ can be determined by dynamic vapour sorption (DVS) [13] from the sorption isotherm using the Gibbs equation. After adsorption of the vapour on the solid surface, the authors observed a decrease of the surface energy of the solid $\left(\gamma_{\mathrm{S}}\right)$, using the assumption that the contact angle $\theta$ is zero $(\operatorname{Cos} \theta=1)$ and simplifying the equation of Young. Comte et al. [13] calculated also the work of adhesion values using the extended Fowkes's model that links the work of adhesion to the surface energy, which is defined as 
the sum of the dispersive and polar components. They also showed that gravimetric method was more suitable with condensable vapours (water, alcohols, alkanes, benzene etc...) at ambient temperature.

Helmy et al. used a new approach to describe the surface energy of montmorillonite based on liquid/solid interactions [14]. The Young equation was used to calculate $\gamma_{\mathrm{s}}$, the surface tension of the liquid $\left(\gamma_{\mathrm{L}}\right)$ and the solid/liquid contact angle $(\theta)$. The surface energy values determined in water were $205.06 \pm 2.76 \mathrm{~mJ} . \mathrm{m}^{-2}$ for montmorillonite (swelling clay), $151.80 \pm 34.98 \mathrm{~mJ} . \mathrm{m}^{-2}$ for bentonite [15], and 59.00 $\mathrm{mJ} . \mathrm{m}^{-2}$ for kaolinite [16]. The zeta potential as function of $\mathrm{pH}$ can also be used to assess the surface properties of clay minerals such as kaolinite [17]. The point of zero charge of kaolinite was determined using electrophoresis and electroacoustic mobility measurements [18].

This study aims at investigating the influence of calcination and acid activation of mineral clays on its surface properties using various analytical and spectroscopic tools and to evaluate how such treatments could be used for generating novel clay mineral products with enhanced surface properties for some specific needs in materials engineering.

\section{EXPERIMENTAL SECTION}

\section{Starting Materials}

This study tries to characterize the clays of the region of Zaghouan after heating and acid activation treatments in order to utilize them in modern industrial applications. The raw clay from the region of Zaghouan was crushed and then dispersed in a 1 mol. $\mathrm{l}^{-1}$ sodium chloride solution $(\mathrm{NaCl})$. The clay fraction was extracted by sedimentation and washing with distilled water several times. Then, the solid was dried, crushed and finally heated at $550{ }^{\circ} \mathrm{C}$ during $1 \mathrm{~h}$ (hereafter designated as Ar-0). The acid activation was performed by

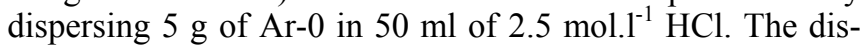
persion was maintained under magnetic stirring at $60{ }^{\circ} \mathrm{C}$ for 1-24 $\mathrm{h}$ to obtain acid activated samples generically designated as Ar-n (where $\mathrm{n}$ stands for the activation time period in hours). The solid fractions were then separated by centrifugation and subjected to cycles of hot washings by distilled water until obtaining a filtrate with $\mathrm{pH}$ close to 5 . Finally, the solid samples thus obtained were dried, crushed and saved for further experiments.

\section{Technical Characterisation}

Chemical analyses were made by spectrophotometry of atomic absorption using the air-acetylene flame for the following chemical elements: $\mathrm{Fe}, \mathrm{Na}, \mathrm{K}$ and $\mathrm{Mg}$ and of nitrous oxide-acetylene for $\mathrm{Ca}$ and $\mathrm{Al}$, and by visible spectrophotometry to determine the chemical elements: Ti, P and Si.

The crystalline phases were identified by X-Ray powder diffraction (XRD), Philips PW 3011/20 with $\mathrm{Cu} \mathrm{K}_{\alpha}$ radiation $(40 \mathrm{kV}, 40 \mathrm{~mA}, \lambda=0.154098 \mathrm{~nm})$ using randomly oriented clay particles within the $2 \theta$ range from $5^{\circ}$ to $65^{\circ}$. Three samples were also prepared by dispersing clay in distilled water and spreaded on a slide glass and air dried. The X-Ray diffraction patterns of all these preferentially oriented clay particles were then recorded in the range of $2^{\circ}$ to $75^{\circ}(2 \theta)$. One of these samples was analysed in the as dried condition; a second one was meanwhile saturated with a saturated solution of ethylene glycol and dried again; and the third one was heat treated at $550{ }^{\circ} \mathrm{C}$ for $1 \mathrm{~h}$. The size of crystallites was calculated using the Scherrer equation (1)

$$
\Gamma=\frac{0.94 * \lambda}{\varphi^{*} \cos (\theta)}
$$

where $\Gamma$ is the width with middle height of the most intense peak (in radians); $\varphi$ is the size of crystallites; $\lambda$ is the wavelength of $\mathrm{x}$-rays incidents; $\theta$ is the position of the peak of diffraction. The infrared (IR) spectra were measured by a BX FT-IR spectrometer in the spectral range $4000-400 \mathrm{~cm}^{-1}$. The disk shaped samples were prepared by diluting $2 \mathrm{mg}$ of each powder in $200 \mathrm{mg}$ of $\mathrm{KBr}$ followed by dry pressing. The true density of the powders was assessed by helium pycnometry (Micromeritics Accupyc 1330). $\mathrm{N}_{2}$ adsorption-desorption isotherms at $77^{\circ} \mathrm{K}$ were collected using a volumetric apparatus type Micromeritics ASAP 2010 V5.02. The surface area was calculated according to the BET method. The samples were firstly degassed during one night. Thermogravimetry (TG) and differential scanning calorimeter (DSC) experiments were conducted simultaneously using a TG-DSC 111 SETARAM Calvet apparatus of symmetrical construction. Investigations were made while heating the samples from 30 to $750{ }^{\circ} \mathrm{C}$ at the rate of $2{ }^{\circ} \mathrm{C} \cdot \mathrm{min}^{-1}$ in the nitrogen atmosphere using about $20 \mathrm{mg}$ recording. The gravimetric dynamic vapour sorption (DVS) (Surface Measurement System) technique was used to register the weight changes caused by adsorbing an easily condensable vapour at $35^{\circ} \mathrm{C}$ (Octane or 2-Ispropanol in the present study) within the partial pressure range of 0-1.0 to evaluate the quantity of adsorbed molecules onto the surface of the acid activated clay samples. The apparatus is composed by a micro-balance being able to measure mass variations of about 5 to $6 \mu \mathrm{g}$. Acid activated clay samples not exceeding $0.2 \mathrm{~g}$ were degassed during $60 \mathrm{~min}$ by nitrogen circulation in order to eliminate the undesirable molecules which pollute the surface of the adsorbent. This phase of degasification ensures good reproducibility of the results with a flow of $188 \mathrm{sccm}$ in order to ensure a good balance of adsorption. The relative pressure, $\mathrm{P} / \mathrm{P}^{\circ}$ was varied by steps of $5 \%$ of humidity from 0 to $50 \%$ relative humidity $(\mathrm{RH})$, and then by steps of $10 \%$ from 50 to $90 \% \mathrm{RH}$. These criteria were selected after having carried out preliminary tests and having determined $\mathrm{P} / \mathrm{P}^{\circ}$ necessary to reach the steady state equilibrium.

The value of the Zeta-potentials was measured at $25^{\circ} \mathrm{C}$ in a capillary cell with Zetasizer Nano series (MALVERN, U.K.) instruments. Samples diluted to $\sim 0.05 \mathrm{~g} / 1$ solid content then dispersed for $24 \mathrm{~h}$ in ultrasonic bath and the salt concentration of dilute systems was adjusted to a concentration of $\mathrm{KCl}(0.001 \mathrm{M})$. The $\mathrm{pH}$ of dilute dispersions were adjusted between $\sim 3$ and $\sim 10$ by adding either $\mathrm{HCl}$ or $\mathrm{NH}_{3}$ solutions, and measured directly before introducing sample in to the capillary cell.

\section{RESULTS AND DISCUSSION}

The results of XRD analysis of the preferentially oriented (according to the 001 direction) samples are shown in Fig. (1a). The reflexion at $9.92 \AA$ is characteristic of an illitic clay mineral, denoting the presence clay phase [19]. A peak at 
$18.04 \AA$ appeared after saturating the sample with ethyleneglycol (Fig. 1b), clearly revealing the presence of the smectite phase. On the other hand, the heat treatment at $550{ }^{\circ} \mathrm{C}$ caused the disappearance of kaolinite peaks at $7.12 \AA$ and $3.56 \AA$ [JCPDS card no. 29-1488] and revealed the typical interplanar spacing of dehydrated smectite at $9.96 \AA$ (Fig. 1c). Heating at $550{ }^{\circ} \mathrm{C}$ for $1 \mathrm{~h}$ caused the destruction of the Kaolinite and led to an amorphous phase called metakaolinite. These observations are consistent with the nature of the starting clayey material (a mixture of Kaolinite and Illite and small amount of Smectite).

The results of the chemical analysis of the clay heated at $550{ }^{\circ} \mathrm{C}(\mathrm{Ar}-0)$ and of the sample activated with the hydrochloric acid for $24 \mathrm{~h}$ are given in Table 1. It can be seen that the mass percentage of most of the chemical elements (Al, $\mathrm{K}, \mathrm{Mg}, \mathrm{Fe}, \mathrm{Na}, \mathrm{Ca}, \mathrm{Ti}, \mathrm{P}$ ) decreased after an acid activation. This is probably due to partial dissolution of the clays' structure.

This explains why the percentage of silica has apparently increased slightly, caused by the presence of free quartz. The small decrease in the percentage of $\mathrm{TiO}_{2}$ is likely due to the location of the $\mathrm{Ti}^{4+}$ cations at the octahedral sites. The deterioration extent of the clay structure depends on the heat/acid treatment history underwent by the sample. The activation of a bentonitic clay by sulphuric acid with solutions of various normalities enabled concluding that the cations $\mathrm{K}^{+}$of the illitic structure and the $\mathrm{Si}^{4+}$ tetrahedral sites in both smectite and illite were not affected by acid activation [20]. The amounts of silica and alumina were increased upon heat treating a kaolinite sample at $600{ }^{\circ} \mathrm{C}$, which could be explained by the dehydration of kaolinite and its conversion into an amorphous phase [21]. The acid activation with concentrated $\mathrm{H}_{2} \mathrm{SO}_{4}$ affected the interlayer cations like $\mathrm{K}^{+}$and $\mathrm{Ca}^{2+}$ and progressively reduced the amounts of $\mathrm{Al}, \mathrm{Fe}$ and Mg cations [22].

The XRD patterns of the powder samples activated for different time periods are displayed in Fig. (2). The reflections of free quartz, illite and smectite minerals could still be detected in the spectra of heat treated clay samples. The illitic structure resists to acid attack, quite an obvious phenomenon for the quartz.

Table 2 shows an overall increasing trend of the crystallite size as a function of acid activation time of the preheated clay. The somewhat random variation observed suggests that the crystallites size is not much disturbed by the duration of acid treatment.

The FTIR spectra of the three samples (Ar-0, Ar- 1 and Ar-24) are given in Fig. (3). The assignments of the bands were made according to literature data $[6,23]$. The absorption band centered at about $470-550 \mathrm{~cm}^{-1}$ arises principally from the in-plane vibrations of octahedral ions and their adjacent oxygen layers [23].

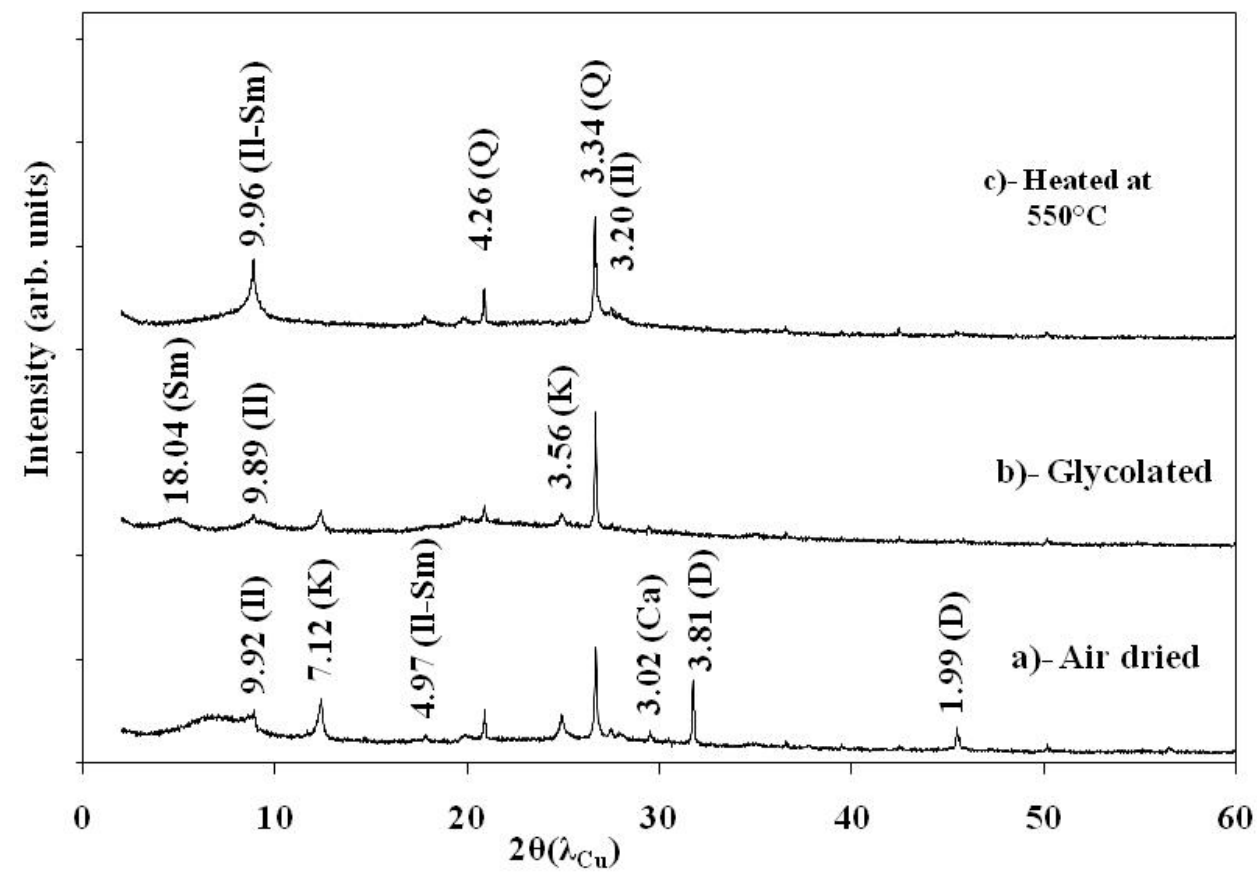

Fig (1). XRD-patterns of the original, ethylene glycol solvated and heated samples (Sm: Smectite, Q: Quartz, Il: Illite, K: Kaolinite, Ca: Calcite, D: Dolomite.

Table 1. Results of the Chemical Analysis of Heat Treated Clay Samples before and after Acid Activation for 24 h (wt.\% of the Corresponding Oxides)

\begin{tabular}{|c|c|c|c|c|c|c|c|c|c|c|c|}
\hline Sample & $\mathbf{M g O}$ & $\mathbf{F e}_{\mathbf{2}} \mathbf{O}_{\mathbf{3}}$ & $\mathbf{N a}_{\mathbf{2}} \mathbf{O}$ & $\mathbf{K}_{\mathbf{2}} \mathbf{O}$ & $\mathbf{C a O}$ & $\mathbf{T i O}_{2}$ & $\mathbf{P}_{\mathbf{2}} \mathbf{O}_{\mathbf{5}}$ & $\mathbf{A l}_{\mathbf{2}} \mathbf{O}_{\mathbf{3}}$ & $\mathbf{S i O}_{\mathbf{2}}$ & LOI (Loss of Ignition) & Total \\
\hline \hline Ar-0 & 0.77 & 2.11 & 1.38 & 2.33 & 2.32 & 1.40 & 0.89 & 13.56 & 69.62 & 4.25 \\
\hline Ar-24 & 0.37 & 1.11 & - & 1.05 & 1.36 & 1.33 & 0.60 & 5.74 & 71.66 & 9.10 \\
\hline
\end{tabular}




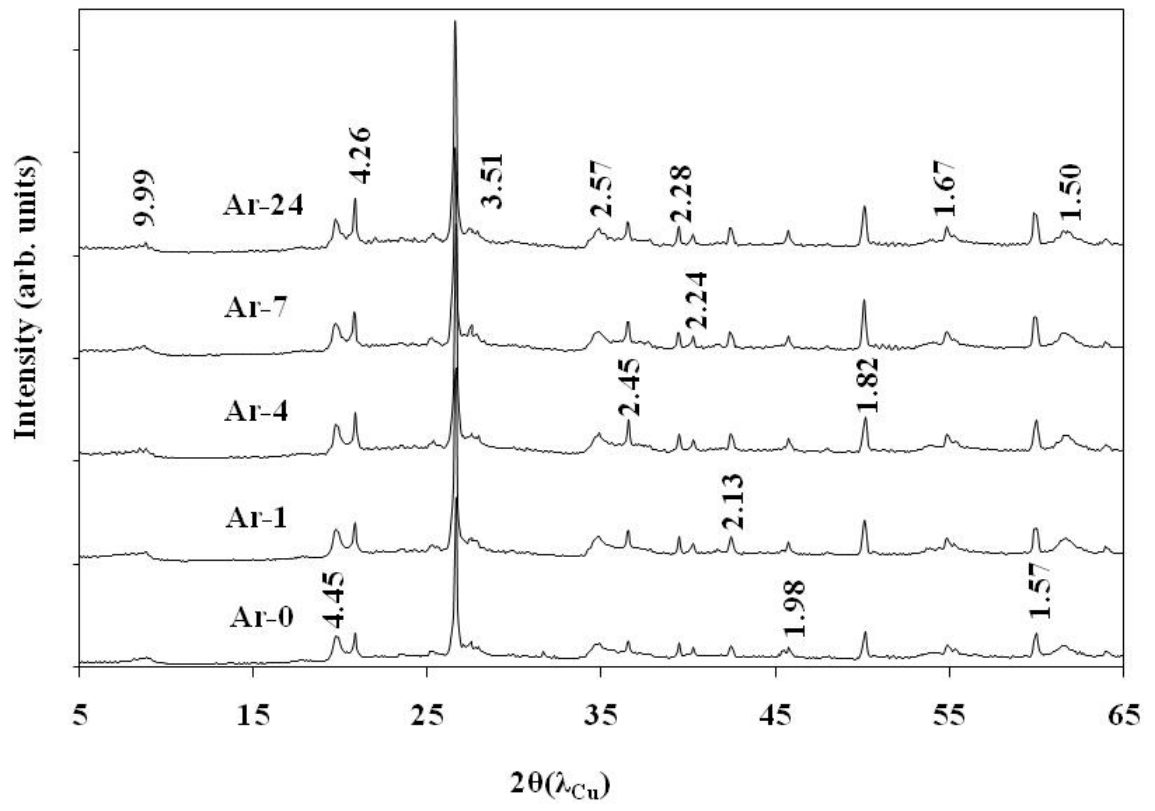

Fig (2). X-ray powder diffractograms of heat treated samples, before and after acid activation for different times.

Table 2. Influence of Acid Activation Time on the Average Size, $\varphi$, of Crystallites

\begin{tabular}{|c|c|c|c|c|c|c|c|c|c|}
\hline Sample & Ar-0 & Ar-1 & Ar-2 & Ar-3 & Ar-4 & Ar-6 & Ar-7 & Ar-17 & Ar-24 \\
\hline \hline Average $\varphi(\mathrm{nm})$ & 26.55 & 33.42 & 36.01 & 32.87 & 27.39 & 34.12 & 33.72 & 33.85 & 32.39 \\
\hline
\end{tabular}

This absorption band, together with that in the region of approximately $950-1200 \mathrm{~cm}^{-1}$ can also be assigned to the antisymmetric stretching vibrations ("stretching vibration") of Si-O-Si. The intensity of these bands decrease with increasing the acid activation time, indicating a fragmentation trend of the tetrahedral layers and the formation of amorphous silica. Besides these main features, the spectra in Fig.
(3) also exhibit absorption peaks at $1640 \mathrm{~cm}^{-1}$, and at about $2400 \mathrm{~cm}^{-1}$, attributed to water and to $\mathrm{CO}_{2}$, respectively.

The measured values of true density revealed that the starting clayey material treated in $\mathrm{NaCl}$ solution was about $2580 \mathrm{~kg} \cdot \mathrm{m}^{-3}$. With the heat treatment at $550{ }^{\circ} \mathrm{C}$ (sample Ar$0)$, the true density increased to about $2609 \mathrm{~kg} \cdot \mathrm{m}^{-3}$. This means that the clayey material becomes denser after heating

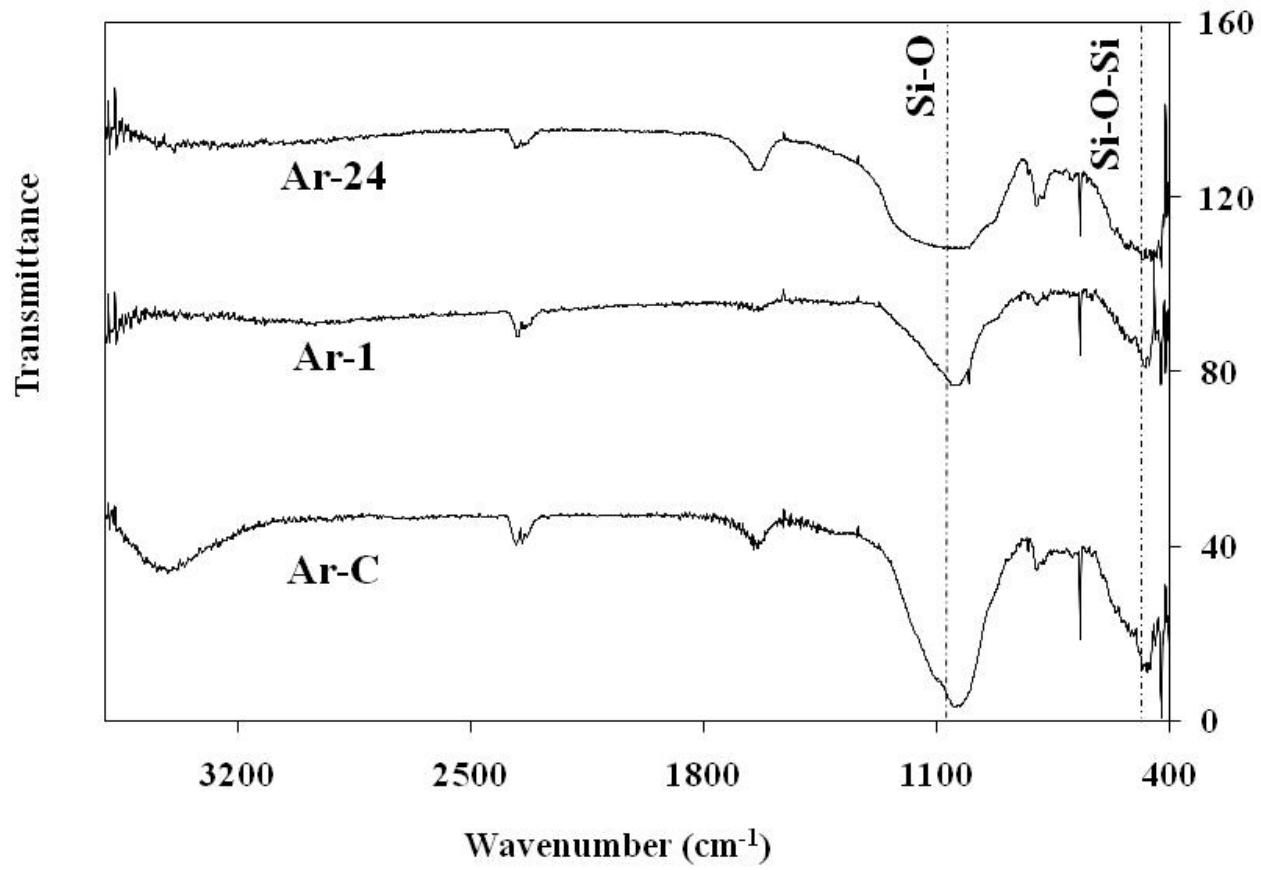

Fig (3). FTIR spectra of heat treated clay samples, before and after acid activation for different times. 
at $550{ }^{\circ} \mathrm{C}$, probably due to the partial collapse of the structure. The true density of the starting clayey material treated in $\mathrm{NaCl}$ solution is close to those given in the work of Konan et al. [24]. For an illite it was about $2630 \mathrm{~kg} \cdot \mathrm{m}^{-3}$ whereas for a montmorillonite it was about $2300 \mathrm{~kg} . \mathrm{m}^{-3}$, and for a kaolinite it was about $2700 \mathrm{~kg} \cdot \mathrm{m}^{-3}$. After acid activation the true density value for Ar-24 sample decreased to $2424 \mathrm{~kg} \cdot \mathrm{m}^{-3}$ showing that acid activating the heat treated samples involves some structural changes, including partial dissolution of some oxides as reported in Table $\mathbf{1}$.

The DSC (Differential scanning Calorimetery as thermoanalytical method) curves of the Ar-0 sample acid activated for different time periods (results not shown) exhibited two endothermic changes at $82^{\circ} \mathrm{C}$ and at $520{ }^{\circ} \mathrm{C}$. The first endothermic peak was attributed to dehydration of interparticle water. The second one was due to the endothermic loss of bound water and to the deshydroxylation of smectite.

The shape of the nitrogen adsorption isotherms at $77 \mathrm{~K}$ (Fig. 4) was not changed by acid treatment.

By application of the BET equation, the specific surface area $\left(\mathrm{S}_{\mathrm{BET}}\right)$ of clay sample was determined according to:

- Adsorption of $\mathrm{N}_{2}$ at $-196{ }^{\circ} \mathrm{C}$ (size nitrogen molecule is of $16.2 \AA^{2}$ ).
- Adsorption of a polar solvent such as isopropanol at 35 ${ }^{\circ} \mathrm{C}\left(63.8 \AA^{2}\right)$.

- Adsorption of an apolar solvent like octane at $35{ }^{\circ} \mathrm{C}$ $\left(43.2 \AA^{2}\right)$.

The specific surface areas obtained by $\mathrm{N}_{2}$ gas adsorption at $77 \mathrm{~K}$, isopropanol and octane adsorption at $308 \mathrm{~K}$ are summarised in Table 3. It can be seen that the $S_{\mathrm{BET}} \mathrm{N}_{2}$ specific surface area decreased from $70.7 \mathrm{~m}^{2} \cdot \mathrm{g}^{-1}$ measured for the starting untreated sample, to about half of that value after thermal treatment at $550{ }^{\circ} \mathrm{C}$, and then significantly increased upon acid activation and with duration of acid attack.

The determination of the surface energy of solids via solid/liquid interfacial interactions depends on the determination of the surface tension of the solid and the solid/liquid interfacial tension. The liquid surface tension $\left(\gamma_{\mathrm{LV}}\right)$ is given by equation (2):

$\gamma_{L V}=\frac{d G_{t}}{d S}$

where $\mathrm{G}$ is the free energy, $\mathrm{S}$ is the surface of the liquid. This surface tension is the sum of two components

$\gamma_{L V}=\gamma_{L V}{ }^{d}+\gamma_{L V}{ }^{s p}$

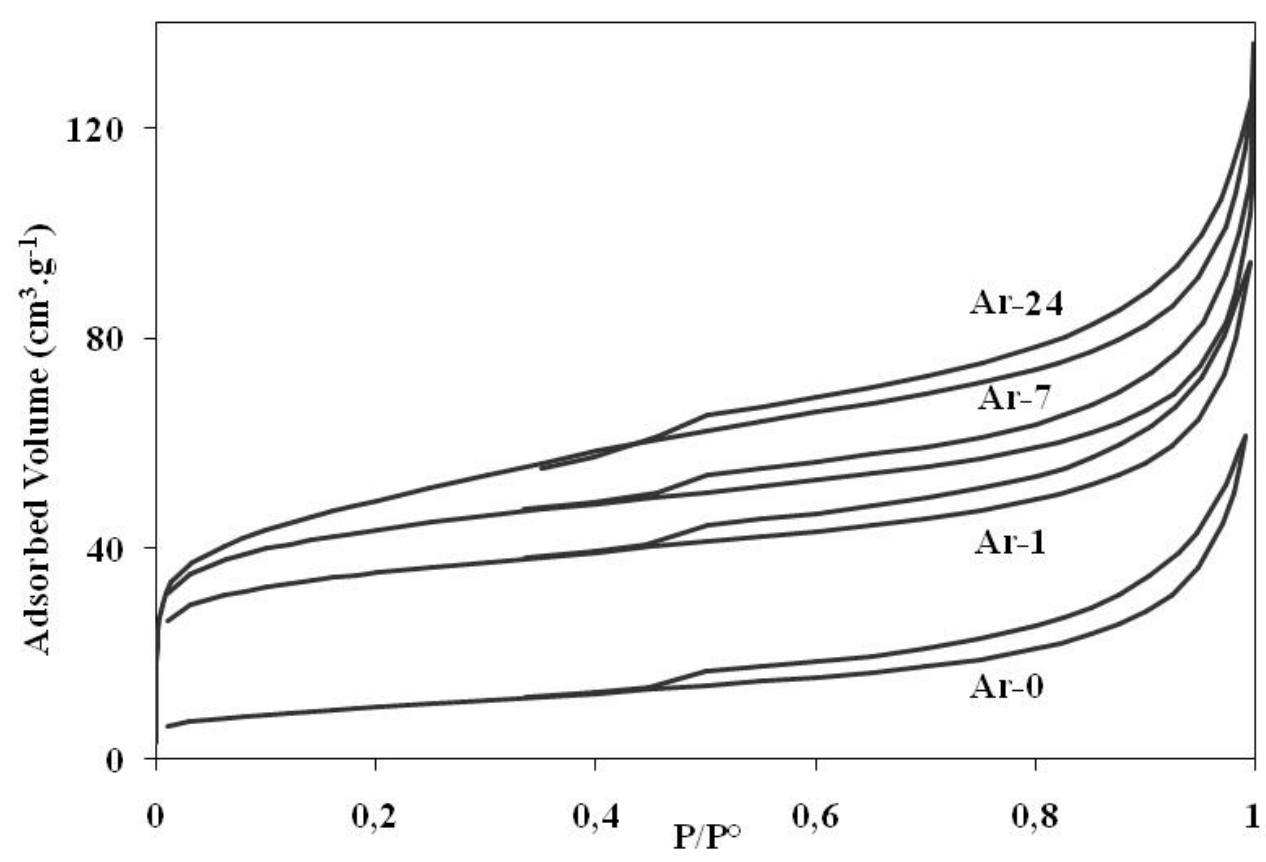

Fig (4). Nitrogen adsorption-desorption isotherms of heat treated clay samples before and after acid activation for 1, 4 and $24 \mathrm{~h}$.

Table 3. Influence of the Treatments Given to the Clay Samples on the Specific Surface area

\begin{tabular}{|c|c|c|c|}
\hline Sample(*) & $\mathrm{S}_{\mathrm{BET}} \mathrm{N}_{2} 77^{\circ} \mathrm{K}\left(\mathrm{m}^{2} \cdot \mathrm{g}^{-1}\right)$ & $\mathrm{S}_{\mathrm{BET}}$ Isopropanol $\mathbf{3 0 8}^{\circ} \mathrm{K}\left(\mathrm{m}^{2} \cdot \mathrm{g}^{-1}\right)$ & $S_{\text {BET }}$ Octane $308^{\circ} \mathrm{K}\left(\mathrm{m}^{2} \cdot \mathrm{g}^{-1}\right)$ \\
\hline Ar-0 & 35.3 & 62.68 & 24.94 \\
\hline Ar-1 & 130.33 & 158 & 72.39 \\
\hline Ar-4 & 147.47 & 158 & 78.51 \\
\hline Ar-24 & 176.08 & 190 & 131 \\
\hline
\end{tabular}

$\left(^{*}\right)$ The $\mathrm{S}_{\mathrm{BET}} \mathrm{N}_{2}$ of the starting untreated sample was $70.7 \mathrm{~m}^{2} \cdot \mathrm{g}^{-1}$. 
Where d: dispersive, Sp: specifique and P: Polar.

$\Delta G_{a d s}=\Delta G_{a d s}{ }^{d}+\Delta G_{a d s} s p$

In a similar manner, the free energy of adsorption onto a solid surface is also a contribution of two terms:

The dispersive forces are always present, whereas the specific forces do not intervene in the case of non-polar molecules. In this case, the components of surface energy could also be expressed as:

$\gamma_{S}=\gamma_{S}{ }^{d}+\gamma_{S}{ }^{s p}$

The first term $\left(\gamma^{\mathrm{d}}\right)$ represents the dispersive interactions (London van der Waals forces) whereas the second $\left(\gamma^{\mathrm{sp}}\right)$ is the specific contribution which depends on the acid base interactions (hydrogen bonding among others...).

The pressure of spreading out $\left(\pi_{\mathrm{e}}\right)$ is defined as the pressure of a gas film adsorbed onto a solid surface, which is calculate by integration of the equation (6) of Gibbs between 0 and $\mathrm{P}$.

$\mathrm{d} \pi_{\mathrm{e}}=\frac{\mathrm{R} \cdot \mathrm{T} \cdot \mathrm{N}}{\mathrm{M} \cdot \mathrm{s}} \mathrm{d} \ln \mathrm{P}$

In this equation, $\mathrm{R}$ is the ideal gas constant, $\mathrm{T}$ is the absolute temperature $(\mathrm{K})$ of the sorption isotherm, $\mathrm{S}$ is the specific surface area of the solid, already calculated by the BET method $\left(\mathrm{S}_{\mathrm{BET}}\right), \mathrm{M}$ is the molar mass of the adsorbate $\left(\mathrm{M}_{\text {Octane }}\right.$ $=114.23 \mathrm{~g} \cdot \mathrm{mol}^{-1}$ or $\mathrm{M}_{\text {Isopropanol }}=60.1 \mathrm{~g} \cdot \mathrm{mol}^{-1}$ in our case) and $\mathrm{N}$ is the adsorbed quantity (in gram per gram of adsorbent). The $\pi_{\mathrm{e}}$ value can be graphically calculated by integrating the area under the curve $\mathrm{N}=\mathrm{f}(\ln \mathrm{P})$ or $\mathrm{N} / \mathrm{p}=\mathrm{f}(\mathrm{P})$, provided that some assumptions are made such as: (i) $\gamma_{\mathrm{LV}}$ must be lower than $\gamma_{\mathrm{S}}$; (ii) The phenomenon brought into play is surface adsorption not absorption; (iii) There are thermodynamic and kinetic equilibrium conditions.

At $25^{\circ} \mathrm{C}$, the surface tension $\left(\gamma_{\mathrm{L}}\right)$ was equal to 21.3 $\mathrm{mN} . \mathrm{m}^{-1}$ for octane, and equal to $21.2 \mathrm{mN} . \mathrm{m}^{-1}$ for isopropanol. For a non-polar molecule such as octane and according to Fowkes et al. (1990) [25], $\gamma_{\mathrm{L}}^{\mathrm{P}}=0, \gamma_{\mathrm{L}}{ }^{\mathrm{d}}=\gamma_{\mathrm{L}}=21.3 \mathrm{mN} \cdot \mathrm{m}^{-1}$. Under these conditions, the work of adhesion, a phenomenon of solid-liquid interface, can be calculated by equation (7):

$W_{a}=2 \cdot \gamma_{L V}+\pi_{e}$
This equation is valid in the case of a solid that is perfectly wet by pure liquid with a null contact angle. It is supposed that $\gamma_{\mathrm{LV}}$ does not vary significantly with the temperature changing from $25^{\circ} \mathrm{C}$ to $35^{\circ} \mathrm{C}$. So, the $\gamma_{\mathrm{LV}}$ values $25^{\circ} \mathrm{C}$ were taken. From the most commonly used expression:

$W_{a}=2 \cdot \sqrt{\gamma_{S}^{d} \cdot \gamma_{L}^{d}}+2 \cdot \sqrt{\gamma_{S}^{s p} \cdot \gamma_{L}^{p}}$

it is possible to calculate the dispersive component since the polar one is null for a non-polar liquid. According to this approach, equation (8) becomes:

$W_{a}=2 \cdot \sqrt{\gamma_{S}^{d} \cdot \gamma_{L}^{d}}$

With $\gamma_{\mathrm{LV}}=\gamma_{\mathrm{L}}{ }^{\mathrm{d}}=21.3 \mathrm{mN} / \mathrm{m}$ for octane, one can deduce the dispersive component $\gamma_{\mathrm{S}}{ }^{\mathrm{d}}$.

For the second liquid, isopropanol the two terms $\gamma_{\mathrm{L}}{ }^{\mathrm{d}}$ and $\gamma_{\mathrm{L}}^{\mathrm{P}}$ are equal to $19.8 \mathrm{mN} \cdot \mathrm{m}^{-1}$ and $1.4 \mathrm{mN} \cdot \mathrm{m}^{-1}$, respectively. Knowing the values of $\mathrm{W}_{\mathrm{a}}$ and $\gamma_{\mathrm{s}}{ }^{\mathrm{d}}$ from measurements using octane, we could determine the surface tension of the solid. Values of $\pi \mathrm{e}, \mathrm{W}_{\mathrm{a}}, \gamma_{\mathrm{s}}{ }^{\mathrm{d}}$ and $\gamma_{\mathrm{s}}^{\mathrm{sp}}$ were summarized in Table 4.

The surface energy of $141.90 \mathrm{~mJ} . \mathrm{m}^{-2}$ is of an order of magnitude similar to those obtained for other Al-silicate minerals [14]. As it can be seen from this table, the samples treated become more hydrophilic especially after $24 \mathrm{~h}$ of acid treatment.

Knowing the values of dispersive and polar surface tension for the isopropanol, $\left(\gamma_{\mathrm{L}}{ }^{\mathrm{d}}=19.8 \mathrm{mN} / \mathrm{m}\right.$ and $\gamma_{\mathrm{L}}{ }^{\mathrm{p}}=1.4$ $\mathrm{mN} / \mathrm{m}), \mathrm{W}_{\mathrm{a}}$ and $\gamma_{\mathrm{s}}{ }^{\mathrm{d}}$ can be deduced from the measurements made for octane using equation (8): $\gamma_{\mathrm{s}}{ }^{\mathrm{d}}+\gamma_{\mathrm{s}}{ }^{\mathrm{sp}}=\gamma_{\mathrm{s}}$.

The values of $\pi_{\mathrm{e}}, \mathrm{W}_{\mathrm{a}}$ and $\gamma_{\mathrm{S}}$ (with its dispersive and specific components) are reported in Table 4. The surface energy is regarded as the physical potential of its reactivity. As it can be seen from Table 4, the acid activated samples became more hydrophilic especially after $24 \mathrm{~h}$ of acid attack.

Zeta potential $(\zeta)$ measurements of the solid-liquid interface can be also used to characterise the solid surfaces. The variation of $\zeta$ potential of our samples as function of $\mathrm{pH}$ (within the $\mathrm{pH}$ range of 3-10) is shown in Fig (5). It can be noticed that all samples have negative $\zeta$ potential values that change from $(-17$ to $-52 \mathrm{mV})$ within the $\mathrm{pH}$ range studied, but with an apparent disturbance at $\mathrm{pH} \sim 4$.5-5.5. According

Table 4. Values of the Pressure of Spreading Out, the Work of Adhesion, the Surface Energy and its Components (Dispersive and Specific) for the Clay Samples. (All Given in $\mathrm{mN} / \mathrm{m}=\mathbf{m J} . \mathrm{m}^{-2}$ )

\begin{tabular}{|c|c|c|c|c|c|c|c|}
\hline \multirow{2}{*}{ Sample } & \multicolumn{2}{|c|}{$\pi_{\mathrm{e}}$} & \multicolumn{2}{|c|}{$\mathbf{W}_{\mathbf{a}}$} & \multirow{2}{*}{$\gamma_{\mathrm{s}}^{\mathrm{d}}$} & \multirow{2}{*}{$\gamma_{\mathrm{s}}^{\mathrm{sp}}$} & \multirow{2}{*}{$\gamma_{\mathrm{s}}$} \\
\hline & Octane & Isopropanol & Octane & Isopropanol & & & \\
\hline Ar- 0 & 30.55 & 43.16 & 73.15 & 85.56 & 62.80 & 79.09 & $\begin{array}{c}141.90 \\
(151.8)^{*}\end{array}$ \\
\hline Ar-1 & 32.76 & 44.97 & 75.36 & 87.37 & 66.66 & 75.75 & 142.41 \\
\hline Ar-4 & 30.73 & 42.77 & 73.33 & 85.17 & 63.11 & 73.27 & 136.39 \\
\hline Ar-24 & 25.85 & 42.59 & 68.45 & 84.99 & 54.99 & 126.27 & $\begin{array}{l}181.27 \\
(205)^{* *}\end{array}$ \\
\hline
\end{tabular}

* for Bentonite, ** for Montmorillonite: [14] 


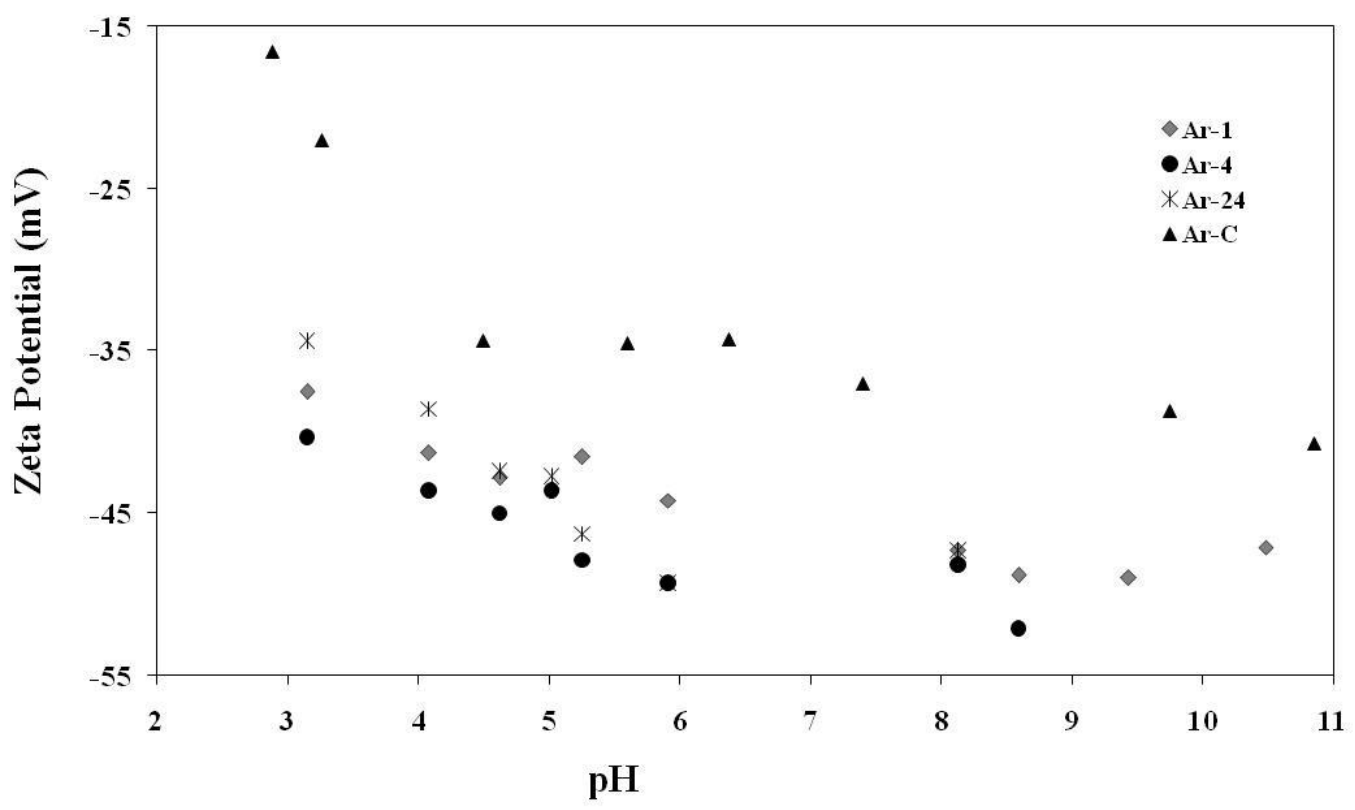

Fig. (5). Zeta potential as a function of $\mathrm{pH}$ for heat treated clay samples after acid activation for 1, 4 and $24 \mathrm{~h}$.

to Hussain et al. (1996) [26], kaolinite has always an overall negative charge. The authors concluded also that all Turkish clays (kaolinite, illite and chlorite) had negative $\zeta$ potential values in distilled water ranging from -13.1 to $-49.5 \mathrm{mV}$. Plate-like clay particles have different crystal structures on edges and basal faces. The basal faces tend to carry a negative electric charge density that is almost independent on $\mathrm{pH}$, while the electric charge sign on their edges is strongly dependent on $\mathrm{pH}$, like the surface of constituting oxides (silica and alumina) [27]. Exposure of the oxide surfaces to water causes the formation of surface hydroxyl groups $(\mathrm{S}-\mathrm{OH})$ that can be ionized. The degree of ionization depends on $\mathrm{pH}$ of the medium and the acid/base reactions occurring at interface particle/solution and may result in surface charge development, as described by equation (10):

$$
\mathrm{S}-\mathrm{OH}_{2}{ }^{+} \stackrel{\mathrm{H}^{+}}{\longleftrightarrow} \mathrm{S}-\mathrm{OH} \stackrel{\mathrm{OH}^{-}}{\longrightarrow} \mathrm{S}-\mathrm{O}^{-}+\mathrm{H}_{2} \mathrm{O}
$$

The predominance of the basal surface area over the area of the edges explains the overall negative $\zeta$-potential curves observed in Fig. (5).

The surface charge intensity is also dependent on the degree of isomorphic substitutions in the lattice. For example, replacing a given cation of valence $n$ for another with a valence of $(n-1)\left(\mathrm{Ct}_{\mathrm{i}}{ }^{n+}\right.$ for $\left.\mathrm{Ct}_{\mathrm{j}}^{(n-1)+}\right)$ is equivalent to adding a negative charge to the bulk material. Isomorphic substitutions in the lattice are very common in clay minerals as those used in the present work. Table $\mathbf{1}$ also reveals that some of the constituting elements were leached off during the acid treatment, being exchanged with hydrogen ions. This was also well perceptible from the colour change of the acid treated samples that became gradually whiter with prolonging the acid treatment. The different leaching degrees obtained after the various acid treatment times might explain the differences in $\zeta$-potential curves observed in Fig. (5). The main differences in $\zeta$-potential curves are observed between the non-leached sample (Ar-0) and the leached ones signifying that the leaching process readily occurs in acid media, and involves the preferential exchange of cationic species from the clay by the abundant hydrogen ions, making the absolute values of $\zeta$-potential to gradually increase.

The above mentioned apparent disturbance within the $\mathrm{pH}$ range of about 4.5-5.5 might be attributed to the combined effects of deprotonation of both siloxane and gibbsite layers [28]. It is also known that alumina usually exhibits a maximum $\zeta$-potential at about $\mathrm{pH}$ 3.5-4 [29], decreasing for higher $\mathrm{pH}$ values due to surface deprotonation. In the neutral $\mathrm{pH}$ region $\zeta$-potential of clay samples is more or less $\mathrm{pH}-$ independent, as expected, since the $\mathrm{pH}$ corresponding to the point of zero charge $\left(\mathrm{pH}_{\mathrm{pzc}}\right)$ at the edge surfaces is approximately at $\mathrm{pH}=7.5$ [29]. The slope of the curve $\zeta$-potential versus $\mathrm{pH}$ increases again for higher $\mathrm{pH}$ values, as a concurrent contribution of deprotonation of silica and alumina surfaces.

\section{CONCLUSION}

The thermal treatment given to the mixture of kaoliniteillite-smectite clay minerals led to structural changes of kaolinite into metakaolinite that were accompanied by a reduction in the specific surface $\mathrm{S}_{\mathrm{BET}}$. The attack by $\mathrm{HCl} 2.5$ mol.1 ${ }^{1}$ at $60{ }^{\circ} \mathrm{C}$ brought further structural modifications especially in the octahedral sheets with leaching off several cations that were exchanged by hydrogen ions and the formation of amorphous silica, as well as textural changes noticed by a significant reduction of density of heat/acid treated clay and about a fivefold increase in specific surface area. These alterations were accompanied by surface energy changes, namely by an overall decrease of the following parameters: pressure of spreading out, $\pi_{\mathrm{e}}$, work of adhesion, $\mathrm{W}_{\mathrm{a}}$, and dispersive interactions, $\gamma_{S}{ }^{d}$. These changes support the increase of the specific interactions, $\gamma_{\mathbf{s}}{ }^{\mathbf{s p}}$, thus increasing the 
surface tension, $\gamma_{\mathrm{S}}$, of the studied clay. As an example the specific energy surface interactions doubled after acid activation for 24 hours.

\section{CONFLICT OF INTEREST}

The authors confirm that this article content has no conflicts of interest.

\section{ACKNOWLEDGEMENTS}

The authors are thankful for the support received from the Foundation for Science and Technology of Portugal (FCT), and from the Ministry of Higher Education, Scientific Research and Technology of Tunisia in the frame of the Joint Research Project Proposal Tunisia - Portugal entitled: "Thermal stability of acid activated clays". The supports from CICECO and from Faculty of Sciences of Tunis, Chemistry Department are also acknowledged.

\section{REFERENCES}

[1] F. Bergaya, B. K.G. Theng and G. Lagaly, Handbook of clay: Development of Clay Science, Elsevier: Amesterdam, vol. 1, 2006.

[2] A. Clearfield, "Preparation of Pillared clays and Their catalytic properties", Advanced Catalysts and Nanostructured Materials, Academic Press: London, pp. 345-394, 1996.

[3] A. Vaccari, "Preparation and catalytic properties of cationic and anionic clays", Research Catalysis Today, vol. 41, pp. 53-57, 1998.

[4] J. Madejová, M. Pentrák, H. Pálková and P. Komadel, “ Nearinfrared spectroscopy: A powerful tool in studies of acid-treated clay minerals", Vibrational Spectroscopy, vol. 49, pp. 211-218, 2009.

[5] M. Önal, and Y. Sarikaya, "Some physicochemical properties of a clay containing smectite and palygorskite", Applied Clay Science, vol. 44, pp. 161-165, 2009.

[6] D. Woumfo, R. Kamga, F. Figueras, and D. Njopwouo, "Acid activation and bleaching capacity of some Cameroonian soil clays", Applied Clay Science, vol. 37, pp. 149-156, 2007.

[7] J.K. Mitechel, "Temperature effects on the engineering properties and behavior of soils", Highway Research Board, Special Report, vol. 103, p. 9, 1969.

[8] M. Tamasan, A. Vulpoi, E. Vanea, and V.Simon, "Textural properties of the medical Algo Clay as influenced by calcinations", Applied Clay Science, vol. 50, pp. 418-422, 2010.

[9] Ozcan, Tan, L. Yilmaz and A. S.Zaimoglu, "Variation of some engineering properties of clays with heat treatment", Materials Letters, vol. 58 pp. 1176-1179, 2004.

[10] F. Caturla, M. Molina-Sabio and F. Rodriguez-Reinso, "Adsorption-desorption of water vapor by natural and heat-treated sepiolite in ambient air", Applied Clay Science, vol.15, pp. 367-380, 1999.

[11] C. Jouany, and P. Chassin, "Determination of the surface energy of clay-organic complexes by contact angle measurements", Colloids and Surfaces, vol. 27, pp. 289-303, 1987.

[12] F. Salles, M. Henry and J.M. Douillard, "Determination of the surface energy of kaolinite and serpentine using PACHA formalism
- Comparison with immersion experiments", Journal of Colloid and Interface Science, vol. 303, pp. 617-626, 2006.

[13] S. Comte, R. Calvet, J.A. Dodds and H. Balard, "Surface properties surface powders using inverse gas chromatography", Powder Technology, vol.157, pp. 39-47, 2005.

[14] A.K. Helmy, E.A. Ferreiro and S. G. Bussetti, "The surface energy of montmorillonite", Journal of Colloid and Interface Science, vol. 268, pp. 263-265, 2003.

[15] A. Vernhet and M. N. Bellon-Fontaine, "Role of bentonites in the prevention of Saccharomyces cerevisiae adhesion to solid surfaces", Colloids and Surfaces B: Bio interfaces, vol. 3, pp. 258, 1994.

[16] V. Medout-Marere, H. Malandrini, T.X. Zoungrana, V. Douillard and S.Partyka, "Thermodynamic investigation of surface of minerals", Journal of Petroleum Science and Engineering, vol. 20, pp. 223-231, 1998.

[17] K. Rodríguez and M. Araujo, "Temperature and pressure effects on zeta potential values of reservoir minerals", Journal of Colloid and Interface Science, vol. 300, pp. 788-794, 2006.

[18] A. Chip, Q. Ma. R. Lena, D. Rhue, and E. Kennelley, "Point of zero charge determination in soils and minerals via traditional methods and detection of electroacoustic mobility", Geoderma, vol.113, pp. 77-93, 2003.

[19] V.A Drits, G. Besson and F. Muller, "An improved model for structural transformations of heat treated aluminous dioctahedral 2:1 layer silicates”, Clay Miner, vol.6, pp. 718-731, 1995.

[20] O. Musseref, and Y. Sarikaya, "Preparation and characterization of acid activated bentonite powders", Powder Technology, vol. 15, p. $172,2007$.

[21] G. Suraj, C.S.P. Iyer and M. Lalithambika, "Adsorption of calcium and copper by modified kaolinites", Applied Clay Science, vol. 13, pp. 293-306, 1998.

[22] W. T. Tsai, H. Hsin-Chich, S. Ting-Yi, L. Keng-Yu, L. ChienMing, and D. Tzong-Hung, "The adsorption of cations dye from aqueous solution onto acid-activated andesite", Journal of Hazardous Materials, pp.147-157, 2007.

[23] Grim, R. E. Clay Minerals, McGraw-Hill: New York, 1968.

[24] K. L. Konan, C. Peyratout, J.P. Bonnet, A. Smith, A. Jacquet, P. Magnoux and P. Ayrault, "Surface properties of kaolin and illite suspensions in concentrated calcium hydroxide medium", Journal of Colloid and Interface Science, vol. 307, pp. 101-108, 2007.

[25] F.M. Fowkes, F.L. Riddle, W.E. Pastore and A.A. Weber, "Interfacial Interactions Between Self-Associated Polar Liquids and Squalane used to Test Equations for Solid-Liquid Interfacial Interactions", Colloids and Surfaces, vol. 43, pp. 367-387, 1990.

[26] S.A. Hussain, S. Demirci and G. Ozbayoglu, "Zeta Potential Mesurements on Three Clays from Turkey and Effects of Clays on Coal Flotation", Journal of Colloid and Interface Science, vol. 184, pp. 535-541, 1996.

[27] G. Tarí, I. Bobos, C.S.F. Gomes and J.M.F. Ferreira, "Modification of surface charge properties during kaolinite to halloysite $7 \AA$ transformation", Journal of Colloid and Interface Science, vol. 210, pp. 360- 366, 1999.

[28] W. Stumm, Chemistry of the Solid-Water Interface, Chap. 3 and 5, John Wiley \& Sons: New York, 1992.

[29] G. Tarì, O. Lyckfeldt, and J.M.F Ferreira, "Influence of Magnesia on Colloidal Alumina", Journal of the European Ceramic Society, vol.17, pp. 1341-1350, 1997. 